\title{
Oncogenic roles of the cholesterol metabolite 25-hydroxycholesterol in bladder cancer
}

\author{
CHEN WANG $^{1}$, HAOWEI HE ${ }^{2}$ and WENNIAN FANG ${ }^{1}$ \\ ${ }^{1}$ Department of Urology, Shanghai Tianyou Hospital Affiliated to Tongji University, \\ Shanghai 200333; ${ }^{2}$ Department of Urology, Jinling Hospital, Nanjing, Jiangsu 210002, P.R. China
}

Received January 19, 2018; Accepted August 8, 2019

DOI: $10.3892 / \mathrm{ol} .2020 .11475$

\begin{abstract}
Oxysterols, such as 24S-hydroxycholesterol and 25-hydroxycholesterol are oxidation products of cholesterol generated by enzymatic reactions. The pathological effects of oxysterols have been described in multiple types of cancer, including cancers of the skin, lung, colon, breast and bile ducts. The molecular mechanisms underlying oxysterol-induced cancer initiation and progression have yet to be completely elucidated, and to the best of our knowledge, no prior data on the role of 24S-hydroxycholesterol and 25-hydroxycholesterol in bladder cancer exists. The results of the present study demonstrated that 25-hydroxycholesterol is increased in bladder cancer tissues, and that it promotes proliferation and the epithelial-to-mesenchymal transition in human T24 and RT4 bladder cancer cells. It was also observed that 25-hydroxycholesterol promotes Adriamycin resistance in T24 and RT4 cells, and that high levels of 25-hydroxycholesterol in bladder cancer are associated with a poor outcome. Therefore, 25-hydroxycholesterol, a primary metabolite of cholesterol, may serve an important role in the progression of bladder cancer.
\end{abstract}

\section{Introduction}

In total, 429,800 new cases of bladder cancer and 165,100 cancer-associated mortalities occurred in 2012, worldwide (1). Bladder cancer is the ninth most commonly-occurring cancer worldwide (2), and is the most common type of urothelial cancer $(3,4)$. The highest incidence rates were observed in men in Southern (age-standardized rate=21.8) and Western Europe (age-standardized rate=19.7), North America (age-standardized rate=19.5), Northern Africa (age-standardized rate $=15.1$ ) and Western

Correspondence to: Dr Chen Wang, Department of Urology, Shanghai Tianyou Hospital Affiliated to Tongji University, 528 Zhennan Road, Shanghai 200333, P.R. China

E-mail: wangchen2018sh@163.com

Key words: 25-hydroxycholesterol, bladder cancer, Adriamycin resistance, epithelial-to-mesenchymal transition
Asia (age-standardized rate=19.0), and the incidence rates are evidently lower in women than men (2). Chemotherapy is an important method for postoperative treatment of bladder cancer (5). However, some patients exhibit poor sensitivity to chemotherapy, leading to poor therapeutic effects (6). Adriamycin is the first line chemotherapy drug for bladder cancer, and primary and secondary resistance of Adriamycin has been observed in bladder cancer (7). Multiple mechanisms are involved in Adriamycin resistance, including increased cancer cell proliferation and epithelial-to-mesenchymal transition (EMT) $(8,9)$.

Oxysterols such as 24S-hydroxycholesterol and 25-hydroxycholesterol constitute a family of oxidized derivatives of cholesterol (10); these metabolites are under investigation as risk markers for multiple outcomes, from cardiovascular disease to cancer (11-24). 24S-hydroxycholesterol has been proposed as a marker for the developmental and pathological changes in the brain $(16,25,26)$. For example, increased circulating 24S-hydroxycholesterol levels is associated with the early stages of late onset Alzheimer's disease (18), and higher concentrations of circulating 24S-hydroxycholesterol levels have been observed in individuals with Alzheimer's disease (18,25). 25-hydroxycholesterol has been investigated with respect to outcomes including breast, colon, and hepatocellular cancer (27). To the best of our knowledge, there are no prior data regarding the role of 24S-hydroxycholesterol and 25-hydroxycholesterol in bladder cancer.

The present study hypothesized that 25-hydroxycholesterol may affect the expression of EMT-associated genes and promote Adriamycin resistance in bladder cancer cells. Thus, it may be a novel prognostic marker for bladder cancer progression and overall patient survival.

\section{Materials and methods}

Analysis of study population and tumor samples. A total of 157 patients with primary bladder cancer were recruited from Shanghai Tianyou Hospital Affiliated to Tongji University and Jinling Hospital between January 1995 and December 2008. The present study enrolled women who were $\geq 18$ years of age and who were diagnosed with primary bladder cancer. Patients with cancer recurrence or with incomplete medical records or inadequate follow-up were excluded. The cohort consisted of 57 female and 100 male patients. The median age of the 
patients was 69 years (range, 41-92 years). Follow-up information was available in all cases.

Tumor samples were obtained directly from surgery following the removal of the necessary amount of tissue for routine pathology examination. All tissue specimens were snap-frozen immediately following collection and stored at $-80^{\circ} \mathrm{C}$. Tumors were graded by the Bergkvist classification system (28). The corresponding adjacent normal tissue sample was obtained $>3 \mathrm{~cm}$ away from the site at which the primary tumor was sampled (29). All tumor tissues and adjacent normal tissues were blindly reviewed by two pathologists from the Department of Urology, Shanghai Tianyou Hospital Affiliated to Tongji University (Shanghai, China). For each patient, comprehensive clinical and pathological data were collected and entered into a Shanghai Tianyou Hospital approved database. Pathological details and UICC TNM classification were also collected (30). The Ethics Committee of Jinling Hospital approved the present study. Written informed consent was obtained from each patient according to The Helsinki Declaration.

Reagents. 24S-hydroxycholesterol and 25-hydroxycholesterol were purchased from Yanke, Inc. (http://xmykswjs.china. herostart.com), and Adriamycin was obtained from Kangbeibio, Inc. (http://www.kangbeibio.com). 24S-hydroxycholesterol $\left(10^{-6} \mathrm{M}\right), 25$-hydroxycholesterol $\left(10^{-6} \mathrm{M}\right)$ and Adriamycin were solubilized in DMSO (Beyotime Institute of Biotechnology).

Bladder cancer cell lines. Human invasive bladder cancer cell lines (T24 and RT4 cells) were obtained from Tiangen Biotech Co., Ltd. T24 and RT4 cell lines have been previously described (31,32). Cells were grown in RPMI-1640 medium (Gibco; Thermo Fisher Scientific, Inc.) supplemented with 10\% FBS (Gibco; Thermo Fisher Scientific, Inc.) and 1\% penicillin/streptomycin (Sigma-Aldrich Merck KGaA). All cell lines were maintained at $37^{\circ} \mathrm{C}$ in a humidified atmosphere with $5 \% \mathrm{CO}_{2}$.

24S-hydroxycholesterol and 25-hydroxycholesterol quantification. 24S-hydroxycholesterol and 25-hydroxycholesterol were quantified in tissue samples using Liquid chromatography-mass spectrometry (LC/MS). Tissues were extracted by crushing in liquid nitrogen, followed by the stepwise addition of distilled $\mathrm{H} 2 \mathrm{O}$. LC/MS was performed as previously described $(33,34)$. Quantitative analysis of 24S-hydroxycholesterol and 25-hydroxycholesterol was performed using Shimadzu LC-20XR HPLC system (Shimadzu Scientific Instruments; https://www.ssi.shimadzu.com), equipped with an ultrasonic degasser, column oven and autosampler.

MTT assay. The effect of 24S-hydroxycholesterol and 25-hydroxycholesterol on the proliferation of bladder cancer cells was assessed via an MTT assay (Sigma-Aldrich, Merck KGaA). The MTT analysis was performed as previously described $(35,36)$. Cells were plated at a density of $8 \times 10^{3}$ cells/well in 96-well plates in DMEM supplemented with $10 \% \mathrm{FBS}$ and incubated at $37^{\circ} \mathrm{C}$ in a $5 \% \mathrm{CO}_{2}$ incubator for $12 \mathrm{~h}$. Cells were treated with $24 \mathrm{~S}$-hydroxycholesterol $\left(10^{-6} \mathrm{M}\right), 25$-hydroxycholesterol $\left(10^{-6} \mathrm{M}\right)$ and vehicle DMSO (control), for $48 \mathrm{~h}$. Subsequently, MTT $(5 \mathrm{mg} / \mathrm{ml})$ was added to the wells (20 $\mu \mathrm{l} /$ well $)$ and the plates were incubated at $37^{\circ} \mathrm{C}$ for $4 \mathrm{~h}$ in a $5 \% \mathrm{CO}_{2}$ incubator. The supernatant was discarded, and the purple formazan crystals were dissolved using $150 \mathrm{ml}$ of DMSO. Following incubation for $10 \mathrm{~min}$ at room temperature, cell viability was measured using a Synergy ${ }^{\mathrm{TM}}$ 4 Multi-Detection Microplate Reader (BioTek Instruments, Inc.), at a wavelength of $570 \mathrm{~nm}$.

Western blot analysis. Western blotting was performed as previously described $(35,36)$. Total protein was extracted from T24 and RT4 cells using extraction buffer comprising $\mathrm{NaCl} / \mathrm{Pi}$ containing $0.5 \%$ Triton X-100, $1 \mathrm{mM}$ EDTA, $1 \mathrm{mM}$ phenylmethyl sulfonyl fluoride and complete protease inhibitors (Roche Diagnostics). Total protein was quantified using a bicinchoninic acid assay kit (Thermo Fisher Scientific, Inc.) and $5 \mu \mathrm{g}$ protein/lane was separated via SDS-PAGE on a $12 \%$ gel. Samples were then transferred onto a nitrocellulose membrane and blocked for $1 \mathrm{~h}$ at room temperature with $5 \%$ skimmed milk powder $(\mathrm{w} / \mathrm{v})$ in $\mathrm{NaCl} / \mathrm{Pi}$. The membranes were incubated with the following primary antibodies: anti-E-cadherin (1:500; cat. no. ab40772), anti-N-cadherin (1:500; cat. no. ab18203;), anti-fibronectin (1:500; cat. no. ab2413) and anti-SOCS3 (1:500; cat. no. ab16030) (all purchased from Abcam), overnight at $4^{\circ} \mathrm{C}$. Following the primary incubation, membranes were incubated with horseradish peroxidase-conjugated anti-rabbit secondary antibodies (1:10,000; cat. no. ab191866; Abcam) for $30 \mathrm{~min}$ at room temperature. Protein bands were visualized using Odyssey ${ }^{\mathrm{TM}}$ Infrared Imaging System (LI-COR Biosciences). $\beta$-actin (1:500; cat. no. ab8226; Abcam) was used as the loading control.

Statistical analysis. Samples were analyzed via Student's t-test for comparison of two groups. One-way Analysis of variance (ANOVA), followed by Bonferroni adjustment was used for the comparison among multiple groups. Data are presented as the mean \pm standard error of the mean. Overall survival was analyzed by Kaplan-Meier methods $(37,38)$. Survival was compared in terms of 25-hydroxycholesterol concentrations. Survival curves were compared via log-rank tests. Hazard ratios with $95 \%$ confidence interval (CI) and P-values are presented. $\mathrm{P}<0.05$ was considered to indicate a statistically significant difference. Statistical analyses were conducted using SAS ${ }^{\circledR}$ software (version 9.4; SAS Institute, Inc.).

\section{Results}

25-hydroxycholesterol is aberrantly upregulated in bladder cancer. In an attempt to identify 24S-hydroxycholesterol and 25-hydroxycholesterol concentrations between bladder cancer tissues and adjacent normal tissues, LC/MS was performed. There was no significant difference in 24S-hydroxycholesterol concentrations between cancer tissues and adjacent normal tissues (Fig. 1A). However, it was observed that the relative levels of 25-hydroxycholesterol were significantly increased in bladder cancer tissues $(\mathrm{P}<0.01$; Fig. 1B).

25-hydroxycholesterol promotes proliferation in T24 and RT4 bladder cancer cells. The capacity of 24S-hydroxycholesterol and 25-hydroxycholesterol to stimulate bladder cancer cell proliferation was evaluated in T24 and RT4 cells with the MTT assay. The results indicated that 24S-hydroxycholesterol 

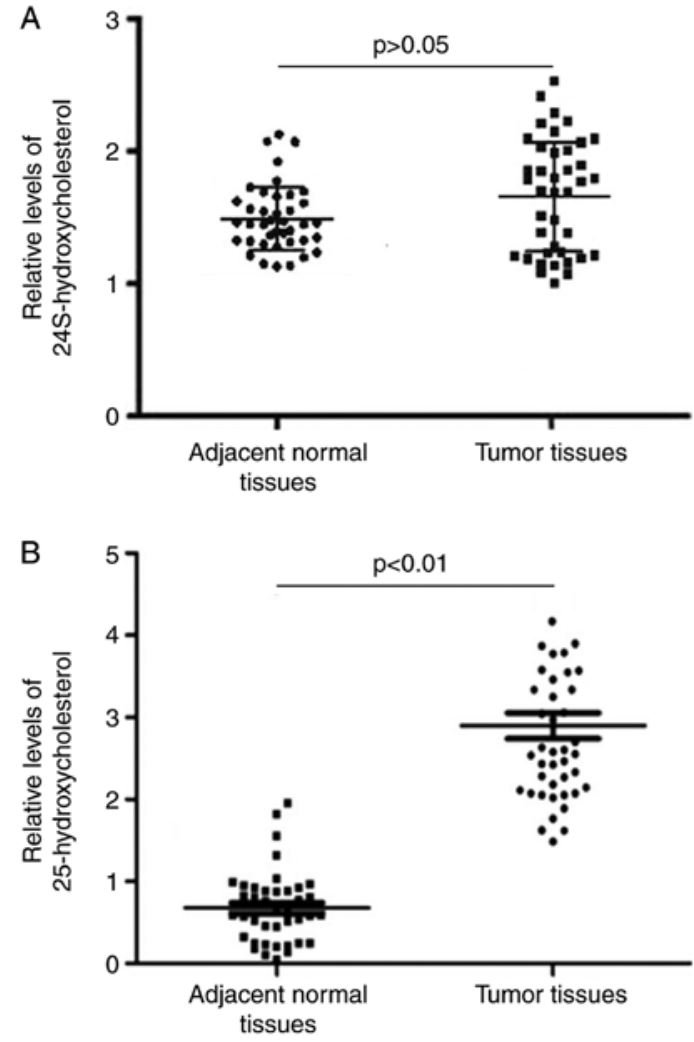

Figure 1. 25-hydroxycholesterol is aberrantly upregulated in bladder cancer. (A) LC/MS for 24S-hydroxycholesterol in 53 bladder cancer tissues and adjacent normal tissues. (B) LC/MS for 25-hydroxycholesterol in 53 bladder cancer tissues and adjacent normal tissues. Error bars indicate standard error of the mean. LC/MS, Liquid chromatography-mass spectrometry.

weakly promoted proliferation in T24 cells (Fig. 2A). 25-hydroxycholesterol significantly promoted proliferation in T24 and RT4 cells (Fig. 2A and B).

25-hydroxycholesterolaffectstheexpressionofEMT-associated genes in T24 and RT4 cells. In order to identify whether 25-hydroxycholesterol could affect EMT in bladder cancer, the present study investigated 3 EMT-associated genes, including E-cadherin, N-cadherin and Fibronectin, and western blot analyses were performed in order to analyze their expression levels. 25-hydroxycholesterol led to a decreased expression level of E-cadherin and increased expressions of $\mathrm{N}$-cadherin and Fibronectin in T24 and RT4 cells (Fig. 3). However, 24S-hydroxycholesterol did not affect E-cadherin, N-cadherin and Fibronectin expression in T24 and RT4 cells (Fig. 3).

25-hydroxycholesterol promotes Adriamycin resistance in T24 and RT4 cells. In order to further identify whether 25-hydroxycholesterol could affect Adriamycin efficacy, the present study performed an MTT assay in T24 and RT4 cells treated as indicated (Fig. 4A and B). It was observed that increased 25-hydroxycholesterol promoted Adriamycin resistance in a dose-dependent manner in T24 and RT4 cells (Fig. 4A and B). The present study also performed western blotting to determine SOCS3 protein expression in T24 and RT4 cells. The results demonstrated that SOCS3 protein expression was increased following treatment with 25-hydroxycholesterol in T24 and RT4 cells (Fig. 4C and D).

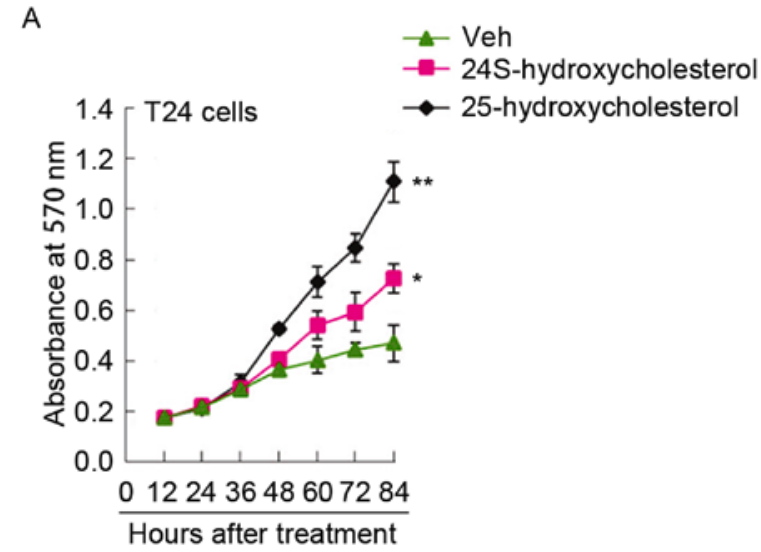

B

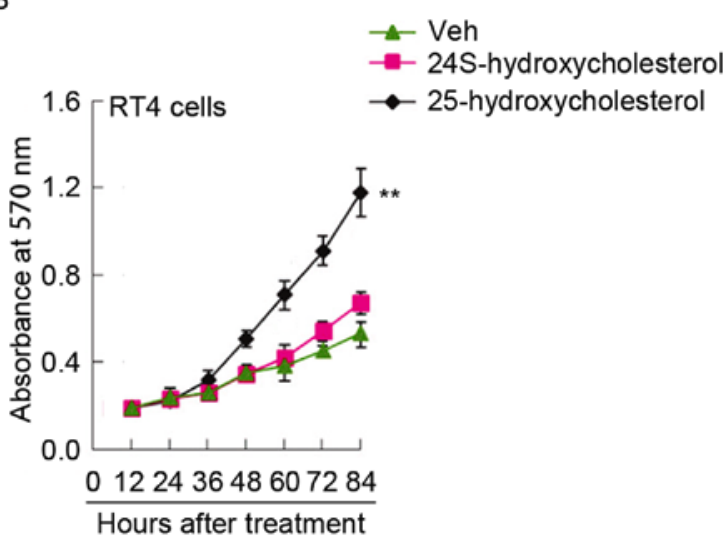

Figure 2. 25-hydroxycholesterol promotes proliferation in T24 and RT4 bladder cancer cells. (A) MTT assay results for cell viability in T24 cells. T24 cells were treated with $24 \mathrm{~S}$-hydroxycholesterol $\left(10^{-6} \mathrm{M}\right), 25$-hydroxycholesterol $\left(10^{-6} \mathrm{M}\right)$ and Veh DMSO. (B) MTT assay results for cell viability in RT4 cells. RT4 cells were treated with $24 \mathrm{~S}$-hydroxycholesterol $\left(10^{-6} \mathrm{M}\right)$, 25-hydroxycholesterol $\left(10^{-6} \mathrm{M}\right)$ and Veh DMSO. Error bars indicate standard error of the mean. ${ }^{*} \mathrm{P}<0.05,{ }^{* * *} \mathrm{P}<0.01$ vs. vehicle treatment group. Veh, Vehicle; DMSO, dimethyl sulfoxide. $\mathrm{n}=3$.

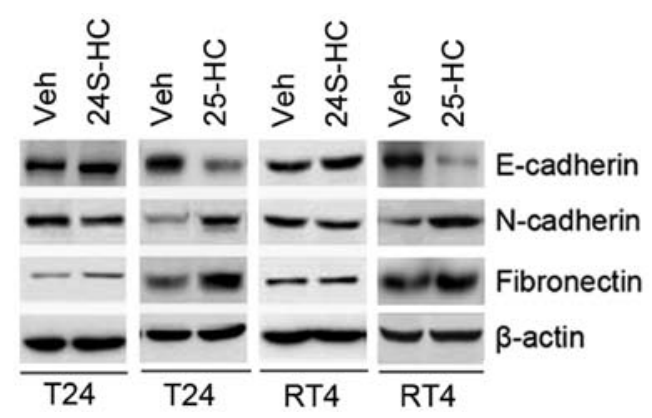

Figure 3. 25-hydroxycholesterol affects the expression levels of epithelial-to-mesenchymal transition-associated genes in bladder cancer cells. Western blot analysis for E-cadherin, N-cadherin and fibronectin protein in T24 cells treated with 24S-hydroxycholesterol and Veh DMSO, 25-hydroxycholesterol and Veh DMSO; and western blot analysis for E-cadherin, N-cadherin and Fibronectin protein in RT4 cells treated with 24S-hydroxycholesterol and Veh DMSO and 25-hydroxycholesterol and Veh DMSO. $\beta$-actin was used as the loading control for all experiments. Veh, Vehicle; DMSO, dimethyl sulfoxide. $n=3$.

25-hydroxycholesterol is a novel prognostic marker for bladder cancer progression and overall patient survival. Kaplan-Meier curves were applied to assess overall survival time for 157 human primary bladder cancers, stratified based 

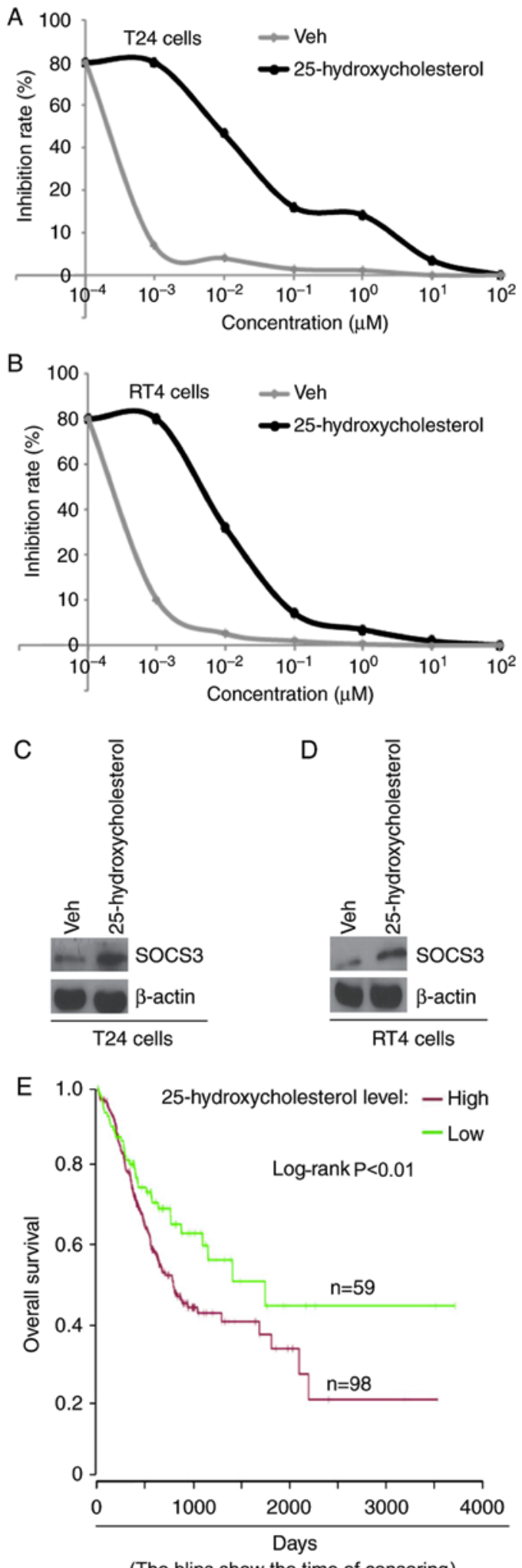

(The blips show the time of censoring)

Figure 4. 25-hydroxycholesterol promotes Adriamycin resistance in T24 and RT4 cells. (A) MTT for cell viability in T24 cells. T24 cells treated with $10^{-6}$ M 25-hydroxycholesterol and Veh DMSO were treated with different concentrations of Adriamycin. (B) MTT for cell viability in RT4 cells. RT4 cells treated with $10^{-6}$ M 25-hydroxycholesterol and Veh DMSO were treated with different concentrations of Adriamycin. Western blot analysis for (C) SOCS3 protein in T24 cells treated with $10^{-6} \mathrm{M} 25$-hydroxycholesterol and Veh DMSO, and for (D) SOCS3 protein in RT4 cells treated with $10^{-6} \mathrm{M}$ 25 -hydroxycholesterol and Veh DMSO. $\beta$-actin was used as the loading control. (E) Kaplan-Meier curves for overall survival of 157 patients with primary bladder cancer. Each drop in the survival curve shows the time of one (or more) patients' death. Veh, Vehicle; DMSO, dimethyl sulfoxide. $n=3$. on concentrations of tumor 25-hydroxycholesterol. Using a log-rank test, the two overall survival curves were significantly different $(\mathrm{P}<0.01$; Fig. 4E). Survival time among patients with high 25-hydroxycholesterol concentrations was much poorer than survival time among patients with low 25-hydroxycholesterol concentrations (Fig. 4E). It is well established that stage and grade are important prognostic factors for bladder cancer (39). In the present study, patients with high-grade tumors had markedly worse survival ( $\mathrm{P}<0.05$; data not shown). Adjustment for tumor stage and grade did not impact the associations between 25-hydroxycholesterol concentrations and overall survival.

\section{Discussion}

Dietary cholesterol is positively associated with the risk of cancers of the breast (primarily postmenopausal), lung, stomach, pancreas, rectum, colon, kidney and bladder (40). In an experimental model, intracellular cholesterol was revealed to be an important component of the cell membrane (41), which in turn is necessary for cancer cell proliferation and metastasis $(42,43)$. In addition, intracellular cholesterol biosynthesis has been proposed as an important mechanism for chemotherapy resistance in bladder cancer cells (44). 25-hydroxycholesterol is synthesized from cholesterol by the enzyme -CYP7B1 (45). A single serum measurement of 25-hydroxycholesterol can reliably estimate its average levels over a 1-year period (33). The present study details an evaluation of the role of 24S-hydroxycholesterol and 25-hydroxycholesterol in bladder cancer. The results obtained suggest that 25-hydroxycholesterol, a primary metabolite of cholesterol, may serve an important role in the progression of bladder cancer.

It has previously been reported that 25-hydroxycholesterol activates ER $\alpha$ in breast cancer MCF-7 cells; it promotes proliferation in MCF-7 and BG-1 ovarian cancer cells; 25-hydroxycholesterol upregulates diverse estrogen target genes; modulates ER $\alpha$ and Cyclin D1 protein levels; stimulates growth in breast and ovarian cancer cells and induces an ER-mediated prevention of hypoxia-dependent apoptosis (46). Consistent with these results of experimental models (46), it was observed in the present study that 25-hydroxycholesterol is aberrantly upregulated in bladder cancer and it promotes proliferation in T24 and RT4 bladder cancer cells.

EMT is a process that exerts pivotal roles in development and wound healing that is characterized by loss of homotypic adhesion and cell polarity, and increased aggressive phenotypes such as invasion and migration (47). At the molecular level, EMT is characterized by loss of epithelial proteins (e.g., E-cadherin and keratin 8) and increased expression of mesenchymal proteins [e.g., fibronectin and $\mathrm{N}$-cadherin (47)]. To the best of our knowledge, the present study is the first to demonstrate that 25-hydroxycholesterol regulates the expressions of EMT-associated genes in bladder cancer cells. These results suggest that increased 25-hydroxycholesterol promotes EMT in bladder cancer. EMT is associated with bladder cancer progression and metastasis, and also monitors drug efficacy (47). Loss of epithelial markers and increased expression of mesen- 
chymal markers have been observed in Adriamycin-resistant cancer cell lines (48). The present study demonstrated that 25-hydroxycholesterol promotes Adriamycin resistance in T24 and RT4 cells and increased 25-hydroxycholesterol is associated with shorter overall survival of bladder cancer patients. In addition, SOCS3 overexpression enhances Adriamycin resistance in T24 bladder cancer cells (6). It was also observed that the protein expression of SOCS3 was increased by 25-hydroxycholesterol in T24 and RT4 cells. Taken together, these results indicate that 25-hydroxycholesterol may promote Adriamycin resistance by regulating SOCS3 expression.

Overall, the present study provided evidence towards the underlying molecular mechanisms and clinical implications for the role of 25-hydroxycholesterol in bladder cancer. 25-hydroxycholesterol is significantly upregulated in human bladder cancer samples, and may act as a crucial regulator, which promotes cells proliferation and EMT in bladder cancer. In addition, 25-hydroxycholesterol is associated with shorter overall survival time and may be a prognostic biomarker for monitoring Adriamycin efficacy and early detection of Adriamycin resistance in bladder cancer.

\section{Acknowledgements}

Not applicable.

\section{Funding}

The present study was funded by Tianyou Hospital Affiliated to Tongji University and Jinling Hospital.

\section{Availability of data and materials}

The datasets used and/or analyzed during the present study are available from the corresponding author upon reasonable request.

\section{Authors' contributions}

CW performed the majority of the experimental work, designed the study and wrote the initial draft of the manuscript. $\mathrm{HH}$ and WF performed the remainder of the experimental work and assisted with the preparation of the manuscript. All authors read and approved the final manuscript.

\section{Ethics approval and consent to participate}

The present study was approved by the Ethics Committee of Jinling Hospital (approval no.20150708) and written informed consent was obtained from all patients at the time of enrollment.

\section{Patient consent for publication}

Not applicable.

\section{Competing interests}

The authors declare that they have no competing interests.

\section{References}

1. Torre LA, Bray F, Siegel RL, Ferlay J, Lortet-Tieulent J and Jemal A: Global cancer statistics, 2012. CA Cancer J Clin 65: 87-108, 2015.

2. Antoni S, Ferlay J, Soerjomataram I, Znaor A, Jemal A and Bray F: Bladder cancer incidence and mortality: A global overview and recent trends. Eur Urol 71: 96-108, 2017.

3. Fan Y, Shen B, Tan M, Mu X, Qin Y, Zhang F and Liu Y: Long non-coding RNA UCA1 increases chemoresistance of bladder cancer cells by regulating Wnt signaling. FEBS J 281: 1750-1758, 2014.

4. Lacey JV Jr, Devesa SS and Brinton LA: Recent trends in breast cancer incidence and mortality. Environ Mol Mutagen 39: 82-88, 2002.

5. Sternberg CN, Donat SM, Bellmunt J, Millikan RE, Stadler W De Mulder P, Sherif A, von der Maase H, Tsukamoto T and Soloway MS: Chemotherapy for bladder cancer: Treatment guidelines for neoadjuvant chemotherapy, bladder preservation, adjuvant chemotherapy, and metastatic cancer. Urology 69 (Suppl): 62-79, 2007.

6. Li MZ, Lai DH, Zhao HB, Chen Z, Huang QX and Situ J: SOCS3 overexpression enhances ADM resistance in bladder cancer T24 cells. Eur Rev Med Pharmacol Sci 21: 3005-3011, 2017.

7. Meng Q, Lei T, Zhang M, Zhao J, Zhao X-H and Zhang M: Identification of proteins differentially expressed in adriamycin-resistant (pumc-91/ADM) and parental (pumc-91) human bladder cancer cell lines by proteome analysis. J Cancer Res Clin Oncol 139: 509-519, 2013.

8. Tsuruo T, Iida H, Nojiri M, Tsukagoshi S and Sakurai Y: Circumvention of vincristine and Adriamycin resistance in vitro and in vivo by calcium influx blockers. Cancer Res 43: 2905-2910, 1983.

9. Li Q-Q, Xu J-D, Wang W-J, Cao XX, Chen Q, Tang F, Chen ZQ, Liu XP and Xu ZD: Twist1-mediated adriamycin-induced epithelial-mesenchymal transition relates to multidrug resistance and invasive potential in breast cancer cells. Clin Cancer Res 15: 2657-2665, 2009.

10. Smith LL: Cholesterol autoxidation 1981-1986. Chem Phys Lipids 44: 87-125, 1987.

11. Nelson ER, Wardell SE, Jasper JS, Park S, Suchindran S, Howe MK, Carver NJ, Pillai RV, Sullivan PM, Sondhi V, et al: 27-Hydroxycholesterol links hypercholesterolemia and breast cancer pathophysiology. Science 342: 1094-1098, 2013.

12. Leoni V, Masterman T, Mousavi FS, Wretlind B, Wahlund LO, Diczfalusy U, Hillert J and Björkhem I: Diagnostic use of cerebral and extracerebral oxysterols. Clin Chem Lab Med 42: 186-191, 2004.

13. Saito Y and Noguchi N: 7-Hydroxycholestrol as a possible biomarker of cellular lipid peroxidation: Difference between cellular and plasma lipid peroxidation. Biochem Biophys Res Commun 446: 741-744, 2014.

14. Hahn C, Reichel C and von Bergmann K: Serum concentration of 7 alpha-hydroxycholesterol as an indicator of bile acid synthesis in humans. J Lipid Res 36: 2059-2066, 1995.

15. Kuroki S, Okamoto S, Naito T, Oda H, Nagase S, Sakai H, Nawata H, Yamashita H, Chijiiwa K and Tanaka M: Serum $7 \alpha$-hydroxycholesterol as a new parameter of liver function in patients with chronic liver diseases. Hepatology 22: 1182-1187, 1995.

16. Koschack J, Lütjohann D, Schmidt-Samoa C and Irle E: Serum 24S-hydroxycholesterol and hippocampal size in middle-aged normal individuals. Neurobiol Aging 30: 898-902, 2009.

17. Bandaru VVR and Haughey NJ: Quantitative detection of free 24S-hydroxycholesterol, and 27-hydroxycholesterol from human serum. BMC Neurosci 15: 137, 2014

18. Zuliani G, Donnorso MP, Bosi C, Passaro A, Dalla Nora E, Zurlo A, Bonetti F, Mozzi AF and Cortese C: Plasma 24S-hydroxycholesterol levels in elderly subjects with late onset Alzheimer's disease or vascular dementia: A case-control study. BMC Neurol 11: 121, 2011.

19. Leoni V, Long JD, Mills JA, Di Donato S and Paulsen JS; PREDICT-HD study group: Plasma 24S-hydroxycholesterol correlation with markers of Huntington disease progression. Neurobiol Dis 55: 37-43, 2013.

20. Babiker A, Dzeletovic S, Wiklund B, Pettersson N, Salonen J, Nyyssönen K, Eriksson M, Diczfalusy U and Björkhem I: Patients with atherosclerosis may have increased circulating levels of 27-hydroxycholesterol and cholestenoic acid. Scand J Clin Lab Invest 65: 365-375, 2005. 
21. Ziedén B, Kaminskas A, Kristenson M, Kucinskienê Z Vessby B, Olsson AG and Diczfalusy U: Increased plasma 7 $\beta$-hydroxycholesterol concentrations in a population with a high risk for cardiovascular disease. Arterioscler Thromb Vasc Biol 19: 967-971, 1999.

22. Murakami H, Tamasawa N, Matsui J, Yasujima M and Suda T: Plasma oxysterols and tocopherol in patients with diabetes mellitus and hyperlipidemia. Lipids 35: 333-338, 2000.

23. Linseisen J, Wolfram G and Miller AB: Plasma $7 \beta$-hydroxycholesterol as a possible predictor of lung cancer risk. Cancer Epidemiol Biomarkers Prev 11: 1630-1637, 2002.

24. Prunet C, Petit JM, Ecarnot-Laubriet A, Athias A, Miguet-Alfonsi C, Rohmer JF, Steinmetz E, Néel D, Gambert P and Lizard G: High circulating levels of $7 \beta$ - and $7 \alpha$-hydroxycholesterol and presence of apoptotic and oxidative markers in arterial lesions of normocholesterolemic atherosclerotic patients undergoing endarterectomy. Pathol Biol (Paris) 54: 22-32, 2006.

25. Noguchi N, Saito Y and Urano Y: Diverse functions of 24(S)-hydroxycholesterol in the brain. Biochem Biophys Res Commun 446: 692-696, 2014.

26. Lütjohann D, Papassotiropoulos A, Björkhem I, Locatelli S, Bagli M, Oehring RD, Schlegel U, Jessen F, Rao ML, von Bergmann K, et al: Plasma 24S-hydroxycholesterol (cerebrosterol) is increased in Alzheimer and vascular demented patients. J Lipid Res 41: 195-198, 2000

27. Kloudova A, Guengerich FP and Soucek P: The Role of Oxysterols in Human Cancer. Trends Endocrinol Metab 28: 485-496, 2017.

28. Bergkvist A, Ljungqvist A and Moberger G: Classification of bladder tumours based on the cellular pattern. Preliminary report of a clinical-pathological study of 300 cases with a minimum follow-up of eight years. Acta Chir Scand 130: 371-378, 1965.

29. Fan Y, Shen B, Tan M, Mu X, Qin Y, Zhang F and Liu Y: TGF- $\beta$-induced upregulation of malat1 promotes bladder cancer metastasis by associating with suz12. Clin Cancer Res 20: $1531-1541,2014$

30. Uicc T: Classification of malignant tumours. Wiley-Liss, New York, NY, 2002

31. Huang L, Luo J, Cai Q, Pan Q, Zeng H, Guo Z, Dong W, Huang J and Lin T: MicroRNA-125b suppresses the development of bladder cancer by targeting E2F3. Int J Cancer 128: 1758-1769, 2011.

32. Yoshino H, Chiyomaru T, Enokida H, Kawakami K, Tatarano S, Nishiyama K, Nohata N, Seki $\mathrm{N}$ and Nakagawa M: The tumour-suppressive function of miR-1 and miR-133a targeting TAGLN2 in bladder cancer. Br J Cancer 104: 808-818, 2011.

33. Lu DL, Sookthai D, Le Cornet C, et al: Reproducibility of serum oxysterols and lanosterol among postmenopausal women: Results from EPIC-Heidelberg. Clin Biochem 52: 117-122, 2017.

34. Wu Q, Ishikawa T, Sirianni R, Tang H, McDonald JG, Yuhanna IS, Thompson B, Girard L, Mineo C, Brekken RA, et al: 27-Hydroxycholesterol promotes cell-autonomous, ER-positive breast cancer growth. Cell Rep 5: 637-645, 2013.

35. Liao XH,Lu DL, Wang N,Liu LY, Wang Y,Li YQ, Yan TB, Sun XG, $\mathrm{Hu} P$ and Zhang TC: Estrogen receptor $\alpha$ mediates proliferation of breast cancer MCF-7 cells via a p21/PCNA/E2F1-dependent pathway. FEBS J 281: 927-942, 2014.
36. Varol N, Konac E and Bilen CY: Does Wnt/ $\beta$-catenin pathway contribute to the stability of DNMT1 expression in urological cancer cell lines? Exp Biol Med (Maywood) 240: 624-630, 2015.

37. Metz CE: Basic principles of ROC analysis. Semin Nucl Med 8: 283-298, 1978

38. Zweig MH and Campbell G: Receiver-operating characteristic (ROC) plots: A fundamental evaluation tool in clinical medicine. Clin Chem 39: 561-577, 1993.

39. Wallace DM, Bryan RT, Dunn JA, Begum G and Bathers S; West Midlands Urological Research Group: Delay and survival in bladder cancer. BJU Int 89: 868-878, 2002.

40. Hu J, La Vecchia C, de Groh M, Negri E, Morrison H and Mery L; Canadian Cancer Registries Epidemiology Research Group: Dietary cholesterol intake and cancer. Ann Oncol 23: 491-500, 2012.

41. Mouritsen OG and Bagatolli LA: Lipid domains in model membranes: A brief historical perspective. Essays Biochem 57: 1-19, 2015.

42. Chichili GR and Rodgers W: Cytoskeleton-membrane interactions in membrane raft structure. Cell Mol Life Sci 66 2319-2328, 2009.

43. George KS and Wu S: Lipid raft: A floating island of death or survival. Toxicol Appl Pharmacol 259: 311-319, 2012.

44. Hamm R, Chen Y-R, Seo E-J, Zeino M, Wu CF, Müller R, Yang NS and Efferth T: Induction of cholesterol biosynthesis by archazolid B in T24 bladder cancer cells. Biochem Pharmacol 91: 18-30, 2014

45. Bauman DR, Bitmansour AD, McDonald JG, Thompson BM, Liang G and Russell DW: 25-Hydroxycholesterol secreted by macrophages in response to Toll-like receptor activation suppresses immunoglobulin A production. Proc Natl Acad Sci USA 106: 16764-16769, 2009.

46. Lappano R, Recchia AG, De Francesco EM, Angelone T, Cerra MC, Picard D and Maggiolini M: The cholesterol metabolite 25-hydroxycholesterol activates estrogen receptor $\alpha$-mediated signaling in cancer cells and in cardiomyocytes. PLoS One 6: e16631, 2011.

47. McConkey DJ, Choi W, Marquis L, Martin F, Williams MB, Shah J, Svatek R, Das A, Adam L, Kamat A, et al: Role of epithelial-to-mesenchymal transition (EMT) in drug sensitivity and metastasis in bladder cancer. Cancer Metastasis Rev 28: 335-344, 2009

48. Sommers CL, Heckford SE, Skerker JM, Worland P, Torri JA, Thompson EW, Byers SW and Gelmann EP: Loss of epithelial markers and acquisition of vimentin expression in adriamycinand vinblastine-resistant human breast cancer cell lines. Cancer Res 52: 5190-5197, 1992.

This work is licensed under a Creative Commons Attribution-NonCommercial-NoDerivatives 4.0 International (CC BY-NC-ND 4.0) License. 